\title{
Adsorptive removal of bisphenol A using synthesized magnetite nanoparticles
}

\author{
B. O. Orimolade ${ }^{1} \cdot$ F. A. Adekola ${ }^{1} \cdot$ G. B. Adebayo ${ }^{1}$
}

Received: 16 January 2017 / Accepted: 23 February 2018 / Published online: 2 March 2018

(C) The Author(s) 2018. This article is an open access publication

\begin{abstract}
Bisphenol A (BPA) is an organic compound which is often used as plasticizer and has been reported to be hazardous to man. In this research the efficiency of removal of BPA from water by magnetite through adsorption process was studied. The magnetite was synthesized using reverse co-precipitation method and fully characterized. Various physicochemical parameters affecting the adsorption of BPA using magnetite were studied as well. The optimum time for the adsorption process was found to be $60 \mathrm{~min}$ at $\mathrm{pH}$ of 6 , adsorbent dose of $0.2 \mathrm{~g}$ and $50 \mathrm{ppm}$ of BPA. The adsorption data were fitted by the Langmuir adsorption isotherm best with a regression value of 0.957 . The $R_{\mathrm{L}}$ value was 0.179 which revealed that the process is favorable. The Freundlich constant $n$ which was 1.901 also revealed that the adsorption is normal and favorable. The data were in agreement with the pseudo-second-order kinetics with regression value of 0.98 . From the thermodynamic studies, the process was found to be exothermic and the Gibb's free energy value which was negative showed that the adsorption was spontaneous. The synthesized magnetite therefore offers great potential for the remediation of bisphenol A-contaminated media.
\end{abstract}

Keywords Bisphenol A $\cdot$ Magnetite $\cdot$ Adsorption $\cdot$ Kinetics $\cdot$ Isotherms

\section{Introduction}

Bisphenol A (BPA) which has the chemical name 2,2-(4,4-dihydroxy phenyl) propane is an estrogen-like endocrine disrupting chemical (EEDC) with two unsaturated phenolic rings (Jafari et al. 2009). It is an important industrial chemical widely used in polycarbonated plastic as well as epoxy resin, both of which are very practical materials often present in food containers (Staples et al. 1998). The effluents from polycarbonate factories have been found to contain high amounts of BPA around $100 \mathrm{mg} / \mathrm{L}$ (Yeo and Kang 2006; Ivanov et al. 2016). BPA either enters the environment during the factory processing and thereby pollutes the rivers and groundwater, sediments in the soil and accumulates there or it can be discharged as a waste product into surface and drinking water (Inoue et al. 2008; Santhi et al. 2012).

BPA-containing wastewater can be a source of contamination in aquatic environments and BPA is hazardous to aquatic systems since it threatens the life of aquaculture

B. O. Orimolade

orimoladeben@yahoo.com; orimolade.bo@unilorin.edu.ng

1 Department of Industrial Chemistry, University of Ilorin, Ilorin, Nigeria through disruption of endocrine glands (Kuramitz et al. 2001; Soares et al. 2008). Low doses of BPA have been reported to cause hypertension, proliferation of prostate cancer cells, heart disease, diabetes, and abnormalities in liver enzymes in humans (Vandenberg et al. 2007; Hugo et al. 2008).

Therefore, the removal of BPA from aquatic environments is of great significance and several methods have been applied for the treatment of water containing BPA, including physical/chemical adsorption (Joseph et al. 2011; Fan et al. 2011), ultrafiltration (Heo et al. 2012), photoelectrocatalytic (Brugnera et al. 2010), biological reduction (Chen et al. 2006), ultraviolet light irradiation (Irmak et al. 2005), catalyzed oxidation method (Coleman et al. 2005) and separation by membrane process (Wu et al. 2010). Since most of these methods have certain disadvantages such as high cost, the formation of hazardous by-product, low efficiency, etc., adsorption process has been found to be very effective for the removal of phenolic compounds (Ahmaruzzaman 2008; Rastegari et al. 2016). Many adsorbents including lignin (Han et al. 2012), activated carbon (Nakanishi et al. 2002), carbon nanotubes (Pan et al. 2008), chitosan (Dehghani et al. 2016) have been investigated for the removal of BPA. 
Recently, nanoparticles have proven to be good adsorbents for the removal phenolic compounds from contaminated water since they possess large surface area. Iron oxide has attracted attention in adsorption process because they are environmental friendly (Zou et al. 2016). In fact iron oxides especially magnetite nanoparticles have been used as adsorbents to remove phenolic compounds from water (Shirsath and Shrivastava 2015). Magnetite is blessed with outstanding sorption capacity, separation property, small size and low toxicity (Wang et al. 2016). Magnetite composites have been reportedly used for the removal of BPA to facilitate the separation of adsorbents from solutions after adsorption (Zhang et al. 2014; Park et al. 2015; Balci and Erkurt 2017). Magnetite has also been applied as a catalyst for catalytic degradation of BPA (Tang et al. 2011; Du et al. 2016). In this work, the efficiency of removal of BPA from water by magnetite through adsorption process was studied. The factors affecting the adsorption process were also investigated to determine the optimal conditions for the sorption of BPA onto magnetite nanoparticles.

\section{Experimental procedures}

The materials used for this research are of analytical grade and include bisphenol A (99\% Purity from Sigma Aldrich)), ferrous chloride, ferric chloride, acetone and sodium hydroxide was obtained from Chemical store in University of Ilorin, Nigeria, supplied by Merck.

Reverse co-precipitation method was employed for the synthesis of the magnetite nanoparticles. This was done by dissolving $21.26 \mathrm{~g}(0.02 \mathrm{~mol})$ of $\mathrm{FeCl}_{3} \cdot 6 \mathrm{H}_{2} \mathrm{O}$ and $7.95 \mathrm{~g}$ (0.01 mol) of $\mathrm{FeCl}_{2} \cdot 4 \mathrm{H}_{2} \mathrm{O}$ in $20 \mathrm{ml}$ deionized water at $25^{\circ} \mathrm{C}$ for $20 \mathrm{~min} .8 \mathrm{~mol} / \mathrm{L}$ of alkaline solution was prepared by adding $13.74 \mathrm{~g}$ of $\mathrm{NaOH}$ to $42 \mathrm{~mL}$ of deionized water and stirred for $30 \mathrm{~min}$ at $25{ }^{\circ} \mathrm{C}$. Magnetic nanoparticles were then precipitated by adding the iron salts solution drop wisely into the $\mathrm{NaOH}$ solution at $80{ }^{\circ} \mathrm{C}$ with continuous stirring. The co-precipitated samples were then washed with deionized water and acetone to remove the $\mathrm{NaCl}$ (Hamid et al. 2012).

The synthesized material was then characterized with appropriate instrumentations. Phase composition of the material was analyzed using X-ray diffractometer. The mean crystallite size of the samples was calculated by XRD linebroadening technique using Scherrer formula. Scanning electron microscopy (SEM) was used to determine the surface morphology of the sample, X-ray fluorescence (XRF) examined the elemental composition and Fourier transform infrared (FTIR) was used to determine the functional groups present.

The magnetite particles were then applied as an adsorbent to remove BPA from aqueous solutions using the batch adsorption process. This was done by introducing a specific mass of the magnetite $(0.1 \mathrm{~g})$ to different concentrations of BPA $(10,20,50,75 \mathrm{ppm})$. The solutions were then placed in the rotary shaker for $45 \mathrm{~min}$ at $30^{\circ} \mathrm{C}$. The concentrations of BPA left in the solutions after removing the magnetite were then determined using the UV spectrophotometer. The quantity of BPA adsorbed onto magnetite was then estimated using Eq. 1:

$q_{\mathrm{e}}=\frac{C_{\mathrm{o}}-C_{\mathrm{e}}}{M} \mathrm{XV}$,

where $C_{0}$ is the initial sorbate concentration $(\mathrm{mg} / \mathrm{L}), C_{\mathrm{e}}$ the equilibrium adsorbate concentration $(\mathrm{mg} / \mathrm{L}), V$ is the volume of solution ( $\mathrm{L}$ ) and $M$ is the mass of the adsorbent $(\mathrm{g})$.

The experimental data from the sorption studies were modeled using the Langmuir, Freundlich and Temkin isotherms. The Langmuir which predicts monolayer coverage of the adsorbate molecules on the outer surface of the adsorbent has the linear form as shown in Eq. 2 (Adekola et al. 2014):

$\frac{C_{\mathrm{e}}}{q_{\mathrm{e}}}=\frac{C_{\mathrm{e}}}{q_{\mathrm{m}}}+\frac{1}{q_{\mathrm{m}} K_{\mathrm{L}}}$,

where $q_{\mathrm{m}}(\mathrm{mg} / \mathrm{g})$ is maximum monolayer coverage related to adsorption capacity of the adsorbent while $k_{\mathrm{L}}(\mathrm{L} / \mathrm{mg})$ is Langmuir constant related to rate of adsorption. The constants are calculated from the slope and the intercept of the plot of Ce/ $\mathrm{q}_{\mathrm{e}}$ against $\mathrm{C}_{\mathrm{e}}$.

The Freundlich isotherm describes multilayer adsorption on heterogeneous surface of adsorbent (Adekola et al. 2014). Equation 3 is the linear form of Freundlich isotherm:

$\mathrm{Lnq}_{e}=\mathrm{LnK}_{f}+1 / n \mathrm{LnCe}$,

where $K_{\mathrm{f}}(\mathrm{mg} / \mathrm{g})$ is the Freundlich constant indicating adsorption capacity and $\mathrm{n}$ is the adsorption intensity. Both constants are deduced from the slope and the intercept of the plot of $\mathrm{Lnq}_{\mathrm{e}}$ vs LnCe.

Temkin isotherm can be used to determine the interaction between the adsorbate molecules and adsorbent and the linear form is presented in Eq. 4:

$q_{\mathrm{e}}=B \operatorname{Ln} A+B \operatorname{Ln} C_{\mathrm{e}}$,

where $A(\mathrm{~L} / \mathrm{g})$ is the Temkin constant related to maximum binding energy and $B(\mathrm{~J} / \mathrm{mol})$ is the Temkin constant related to heat of sorption which are determined from the plot of $q_{\mathrm{e}}$ vs LnCe.

The pseudo-first-order kinetics, pseudo-second-order kinetics and Elovich models were used to study the kinetics of the adsorption process. 


\section{Results and discussion}

\section{Characterization}

The result of the XRF analysis of the synthesized material is presented in Table 1. The result which revealed the elemental compositions of the sample indicated that $\mathrm{Fe}_{3} \mathrm{O}_{4}$ is predominantly present in the sample with a percentage of $94.4 \%$ along with other metal oxides in trace amount as impurities. This suggested that the synthesized material is indeed an oxide of iron.

The results of SEM, XRD and FTIR are presented in Fig. 1a, b, c, respectively. XRD is used to know the diffraction pattern for particles size. The mineralogical composition of the magnetite was determined by the X-ray diffraction analyses for the qualitative evaluation of the common and predominant phases within the sample.

The XRD patterns of synthesized magnetite has characteristic peaks of magnetite which appeared at 29.5, 36.0 43.5 $57.5,62.5$ corresponding to the (220), (311), (422), (511) and (440) crystal planes of a pure $\mathrm{Fe} 3 \mathrm{O} 4$ with a spinal structure (JCPDS file PDF no. 65-3107). Characteristic peaks of impurities were absent and this result revealed that the synthesized material is magnetite ( $\mathrm{Li}$ et al. 2008).

The SEM image revealed the particles are agglomerated and the surface is coarse with pores which indicated the suitability of the material for adsorbent. The agglomeration could be due to forces such as quantum size-effects.

From the FTIR spectra of the synthesized magnetite has an absorbance peak at $565.14 \mathrm{~cm}^{-1}$ which is attributed to

Table 1 XRF result of the synthesized magnetite

\begin{tabular}{lc}
\hline Compounds & $\begin{array}{c}\text { Concen- } \\
\text { tration } \\
(\%)\end{array}$ \\
\hline $\mathrm{SiO}_{2}$ & 2.60 \\
$\mathrm{Al}_{2} \mathrm{O}_{3}$ & 1.05 \\
$\mathrm{MnO}$ & 0.28 \\
$\mathrm{CaO}$ & 0.12 \\
$\mathrm{~K}_{2} \mathrm{O}$ & 0.03 \\
$\mathrm{P}_{2} \mathrm{O}_{5}$ & 0.19 \\
$\mathrm{Eu}_{2} \mathrm{O}_{5}$ & 0.64 \\
$\mathrm{Re}_{2} \mathrm{O}_{7}$ & 0.10 \\
$\mathrm{~V}_{2} \mathrm{O}_{5}$ & 0.04 \\
$\mathrm{Cr}_{2} \mathrm{O}_{3}$ & 0.06 \\
$\mathrm{Fe}_{3} \mathrm{O}_{4}$ & 94.4 \\
$\mathrm{CuO}$ & 0.05 \\
$\mathrm{ZnO}_{\mathrm{In}_{2} \mathrm{O}_{3}}$ & 0.06 \\
$\mathrm{La}_{2} \mathrm{O}_{3}$ & 0.14 \\
\hline
\end{tabular}

$94.4 \%$ is the percentage of iron oxide in the synthesized material (in bold)
$\mathrm{Fe}-\mathrm{O}$ bond as a result of the formation of ferrite phase. The peak at $3423.65 \mathrm{~cm}^{-1}$ corresponds to $-\mathrm{OH}$ vibration which could be due to the presence of moisture in $\mathrm{KBr}$ used for the analysis (Shirsath and Shrivastava 2015).

\section{Effect of pH and adsorbent dose on adsorption}

The effect of the BPA solution $\mathrm{pH}$ and amount of magnetite used are shown in Fig. 2a, b, respectively. The studies were carried out with $50 \mathrm{ppm}$ of BPA solution for $60 \mathrm{~min}$. The adsorption process was found to be dependent on the $\mathrm{pH}$ of the BPA solution (Fig. 2a). It can be seen that the there was slight increase in the quantity of BPA adsorbed over the acidic $\mathrm{pH}$ range. The quantity adsorbed falls from pH 6 to pH 8 and continues to decrease over the basic $\mathrm{pH}$ range. This is mostly likely due to the $\mathrm{pKa}$ value of BPA and the fact that at basic $\mathrm{pH}$ range, the hydroxyl ions compete with BPA molecules for active sites on the magnetite nanoparticles (Xiao et al. 2012; Jin et al. 2015). Low adsorption capacity observed that lower and higher $\mathrm{pH}$ values could also be attributed to the fact that magnetite nanoparticles are quite unstable at higher and lower $\mathrm{pH}$. Equilibrium adsorption was also observed with adsorbent dose of $0.1 \mathrm{~g}$ (Fig. 2b).

\section{Adsorption isotherms}

The amount of BPA adsorbed increased with increase in concentration up to an optimum concentration of $50 \mathrm{ppm}$ where the amount adsorbed was observed to be $4.511 \mathrm{mg} / \mathrm{g}$ (Fig. 3a). The rapid adsorption at the initial stage was most likely due to the large number of available active sites and high driving force, both of which made BPA molecules transfer rapidly the surfaces and pores of magnetite particles. Shortly afterwards, a drop in the quantity of BPA adsorbed was observed, which could be ascribed to the fewer available adsorption sites and the decrease in the driving force (Jiang et al. 2015). The optimum concentration of $50 \mathrm{ppm}$ was used for further experiment.

The isotherm plots for the adsorption process are shown in Fig. 3b-d, while isotherm parameters calculated from the intercept and slope of the plots are shown in Table 2. The extent of the fitness of data with an isotherm model is determined by the regression value $\left(R^{2}\right)$ of the plot. The experimental data fit best the Langmuir isotherm model with $R^{2}$ value of 0.957 which suggests monolayer coverage of the adsorbent surface. The Langmuir constant $R_{\mathrm{L}}$ value of 0.179 indicates that adsorption process is favorable since it less than 1 (Radu et al. 2015). The Freundlich constant ' $n$ ' further suggests that the adsorption is favorable. The Temkin isotherm plot has the least regression value of 0.862 .

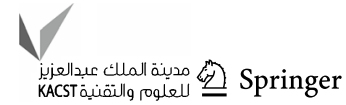




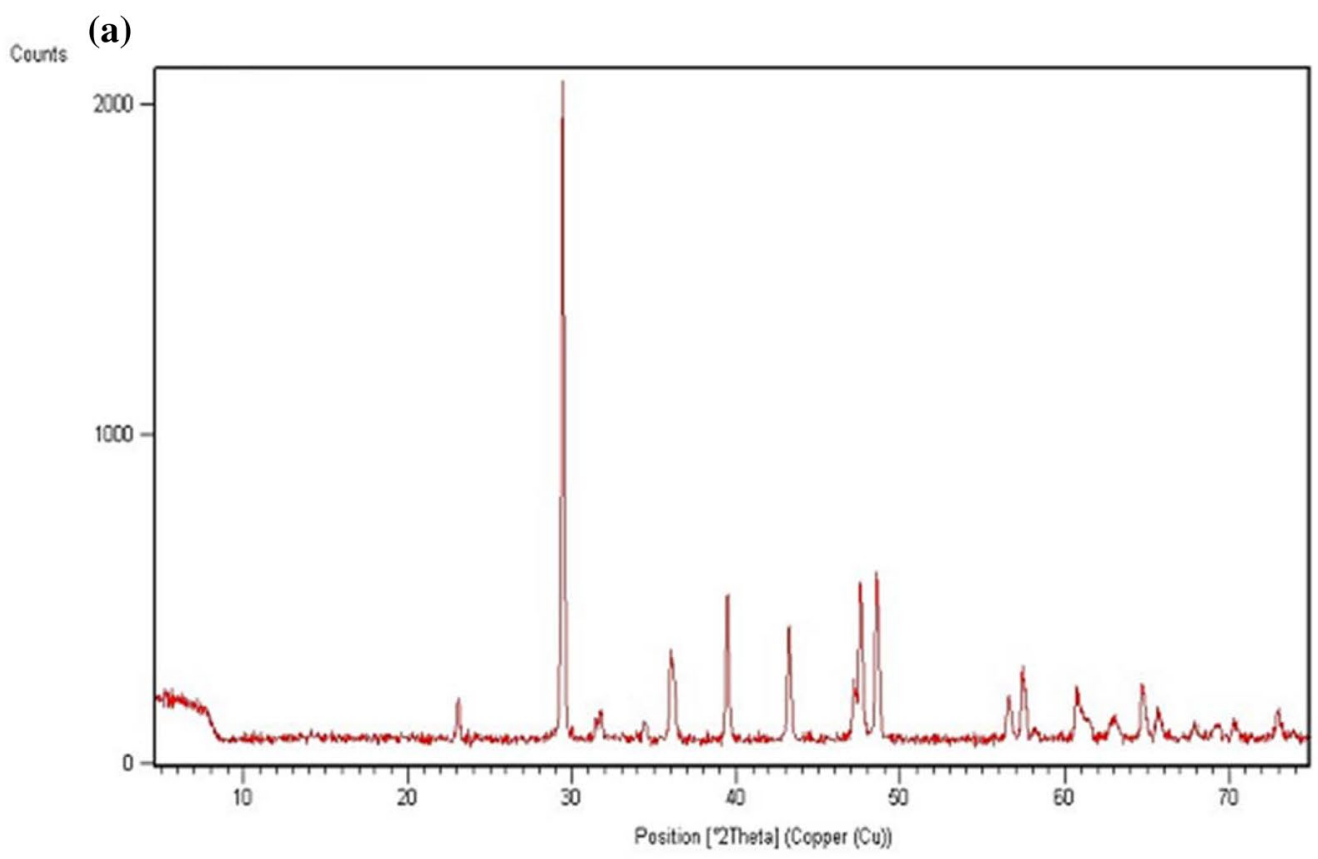

(b)

(c)
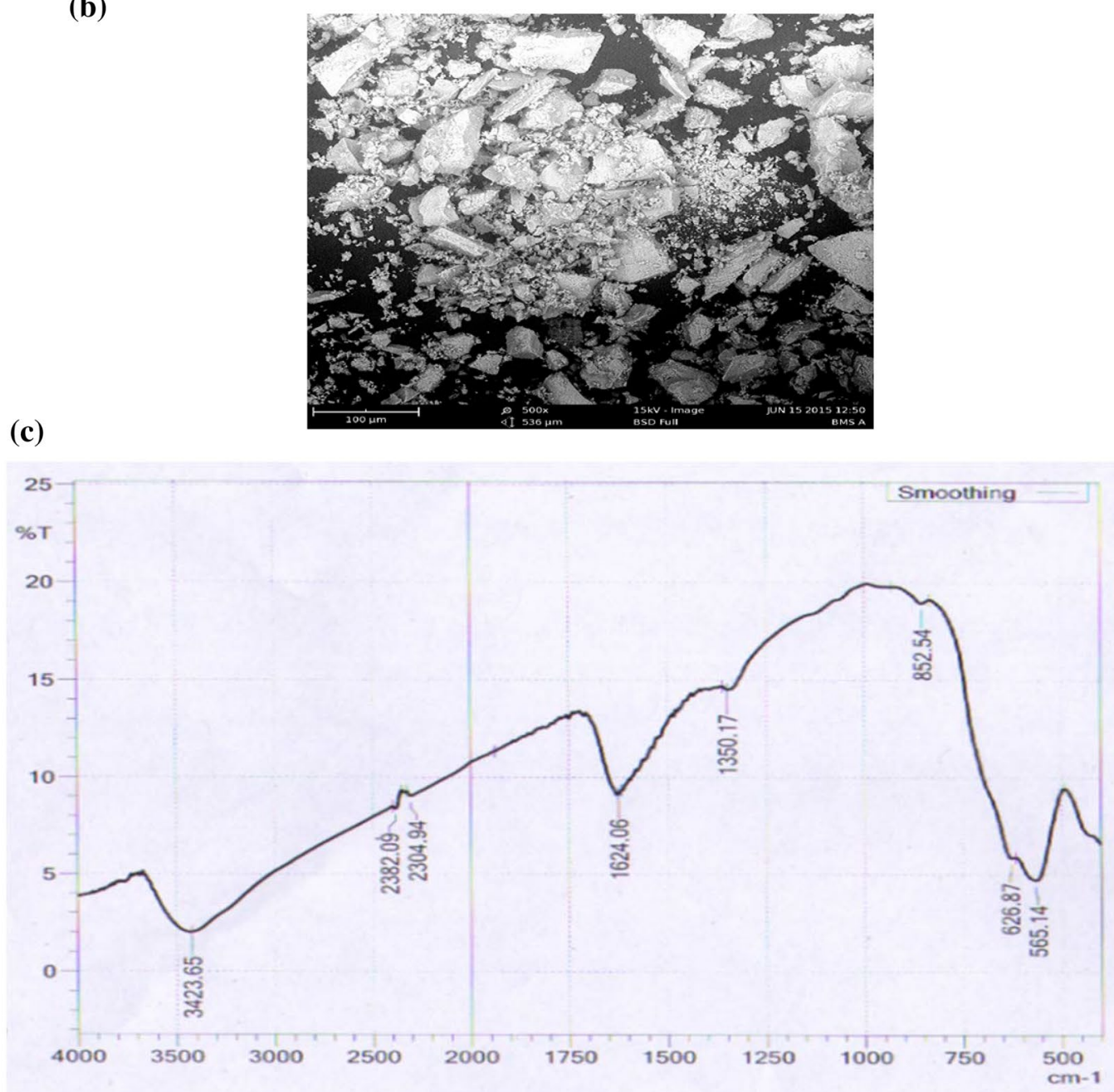

Fig. 1 a XRD image of synthesized magnetite $\left(\mathrm{Fe}_{3} \mathrm{O}_{4}\right)$. b The SEM image of synthesized of magnetite $\left(\mathrm{Fe}_{3} \mathrm{O}_{4}\right)$. $\mathbf{c}$ The FTIR image of synthesized magnetite $\left(\mathrm{Fe}_{3} \mathrm{O}_{4}\right)$ 

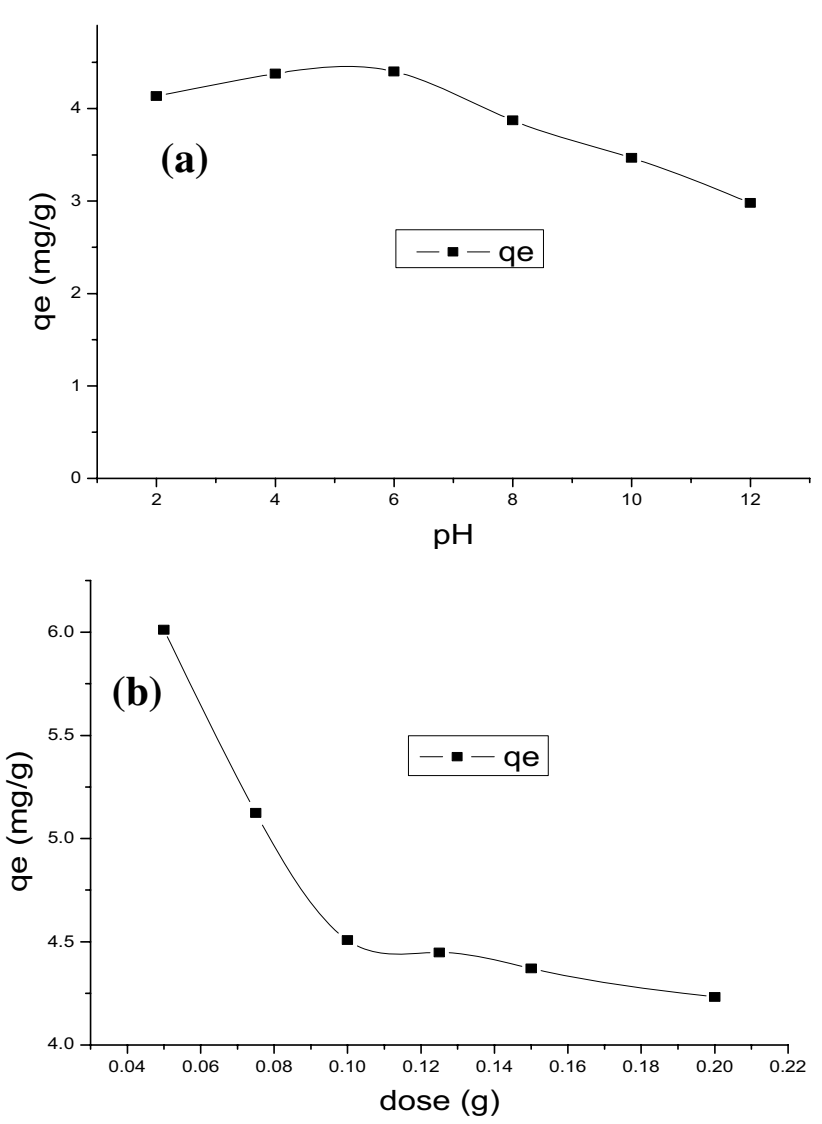

Fig. 2 a Effect of $\mathrm{pH}$ on the sorption of BPA onto $\mathrm{nFe}_{3} \mathrm{O}_{4}$. b Effect of adsorbent dose on the sorption of BPA onto $\mathrm{nFe}_{3} \mathrm{O}_{4}$

\section{Adsorption kinetics}

The uptake of the BPA molecules by the magnetite particles was found to be very rapid within the first few minutes and the uptake reached equilibrium after $60 \mathrm{~min}$ (Fig. 4a). The rapid uptake of BPA can be due to the availability large amounts of adsorption sites in the adsorbent, as the contact time prolongs, there was reduction in the available adsorption sites (Zeng et al., 2006).

The pseudo-first-order, pseudo-second-order and Elovich kinetics plots are presented in Fig. 4b, c, d, respectively, while the parameters calculated from the intercept and slope of the plots are shown Table 3. The experimental data fit the pseudo-second-order kinetics best with $R^{2}$ value of 0.980 . In fact, the experimental quantity adsorbed was found to be very close to the calculated quantity adsorbed and this revealed that the process can best be described by pseudo-second-order kinetics model. This finding is similar to those reported earlier in the literature (Dehghani et al. 2016).
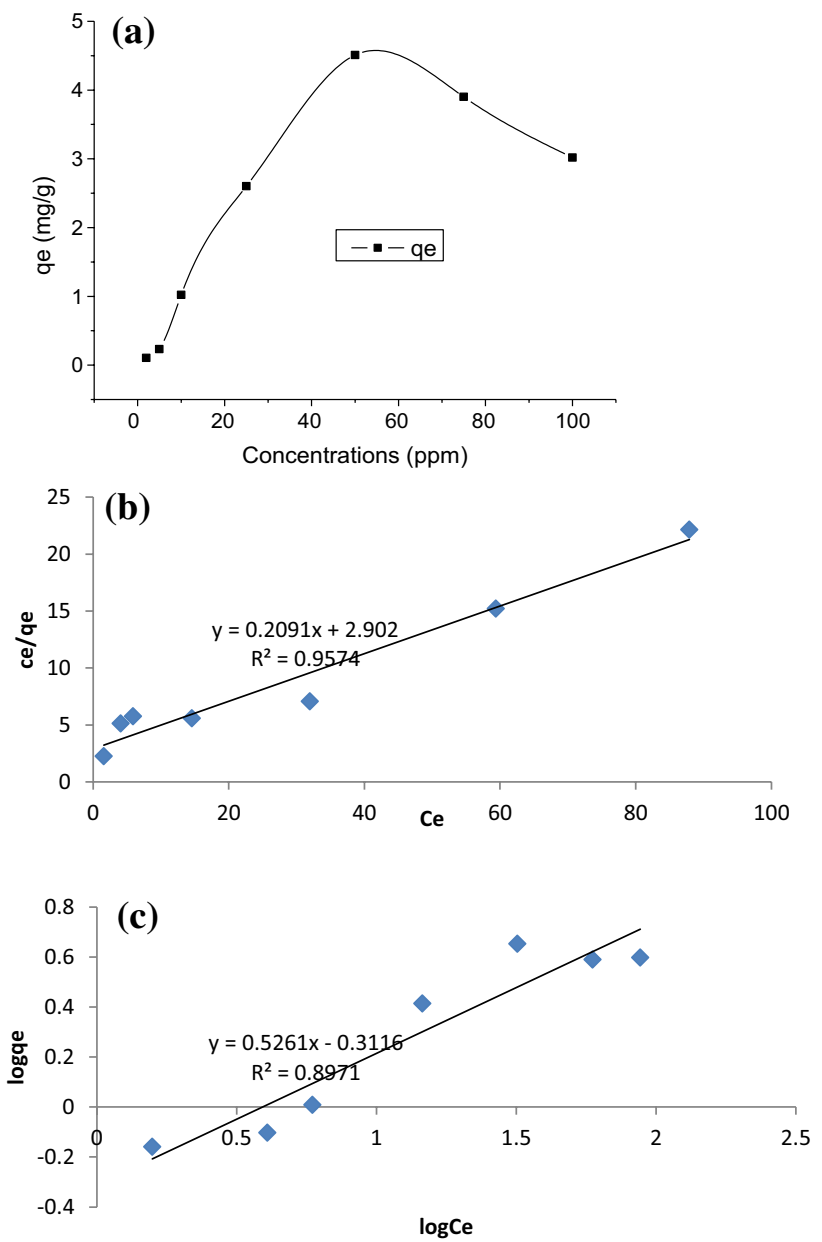

(d)

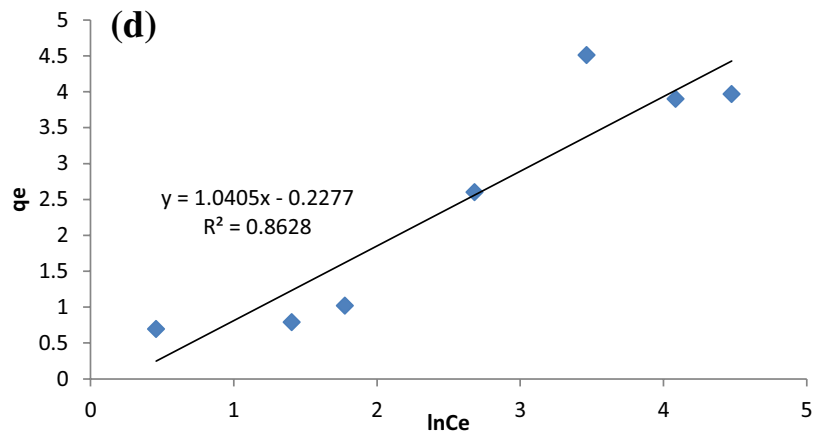

Fig. 3 a Effect of concentration on the sorption of BPA onto $\mathrm{nFe}_{3} \mathrm{O}_{4}$. b Langmuir isotherm plot for the sorption of BPA onto $\mathrm{nFe}_{3} \mathrm{O}_{4}$. $\mathbf{c}$ Freundlich isotherm plot for the sorption of BPA onto $\mathrm{nFe}_{3} \mathrm{O}_{4}$. d Temkin isotherm plot for the sorption of BPA onto $\mathrm{nFe}_{3} \mathrm{O}_{4}$

\section{Thermodynamic studies}

From Fig. 5a, the effect of temperature on the adsorption process can be seen. The temperatures studied are 30, 35, 40, $45,50,55$ and $60{ }^{\circ} \mathrm{C}$. The highest adsorption of BPA onto magnetite was observed at $30{ }^{\circ} \mathrm{C}$ after which the quantity adsorbed decreased slightly. This shows that the process is 
Table 2 Isotherm parameters for the sorption of BPA onto $\mathrm{Fe}_{3} \mathrm{O}_{4}$

\begin{tabular}{llr}
\hline Isotherm & Parameters & Values \\
\hline Langmuir & $Q_{0}(\mathrm{mg} / \mathrm{g})$ & 4.785 \\
& $K_{\mathrm{L}}$ & 0.072 \\
& $R_{\mathrm{L}}$ & 0.179 \\
& $R^{2}$ & 0.957 \\
Freundlich & $K_{\mathrm{f}}$ & 797.995 \\
& $n$ & 1.901 \\
\multirow{3}{*}{ Temkin } & $R^{2}$ & 0.897 \\
& $b_{\mathrm{T}}$ & 1.040 \\
& $A_{\mathrm{T}}$ & 0.804 \\
& $R^{2}$ & 0.862 \\
\hline
\end{tabular}

exothermic and favorable with lower temperature (Liu et al. 2009).

The plot of the thermodynamic studies is shown in Fig. $5 \mathrm{~b}$ and the values of the thermodynamic parameters are presented in Table 4 . The thermodynamic parameters give indications about internal energy changes during the adsorption process. From the results, the enthalpy change $\Delta \mathrm{H}$ was found to be $-26,396.95 \mathrm{Jmol}^{-1}$. The negative value of $\Delta \mathrm{H}$ indicated that the process was exothermic and this was evident in the decrease of adsorption efficiency with increase in temperature. The Gibbs free energy $\Delta G$ was found to be negative at lower temperatures which revealed that at these temperature the adsorption process is feasible and spontaneous. Similar findings have been reported by Radu et al. (2015).

\section{Conclusions}

The removal of BPA from water by magnetite through adsorption process was studied. The magnetite was synthesized using reverse co-precipitation method and fully characterized. The XRF results revealed that iron oxide is the major component of the synthesized material and both XRD and FTIR results confirmed the sample to be nano-magnetite. Various physicochemical parameters affecting the adsorption of BPA using magnetite were studied as well. The optimum time for the adsorption process was found to be $60 \mathrm{~min}$ at $\mathrm{pH}$ of 6 , adsorbent dose of $0.2 \mathrm{~g}$ and $50 \mathrm{ppm}$ of BPA. The adsorption data fit the Langmuir adsorption isotherm best with a regression value of 0.957 . The $R_{L}$ value was 0.179 which revealed that the process is favorable. The Freundlich constant $\mathrm{n}$ which was 1.901 also revealed that the adsorption is normal and favorable. The data were in agreement with the pseudo-second-order kinetics with regression value of 0.98 and the experimental quantity adsorbed is close to the calculated quantity adsorbed. From the thermodynamic studies, the process was found to be exothermic and the
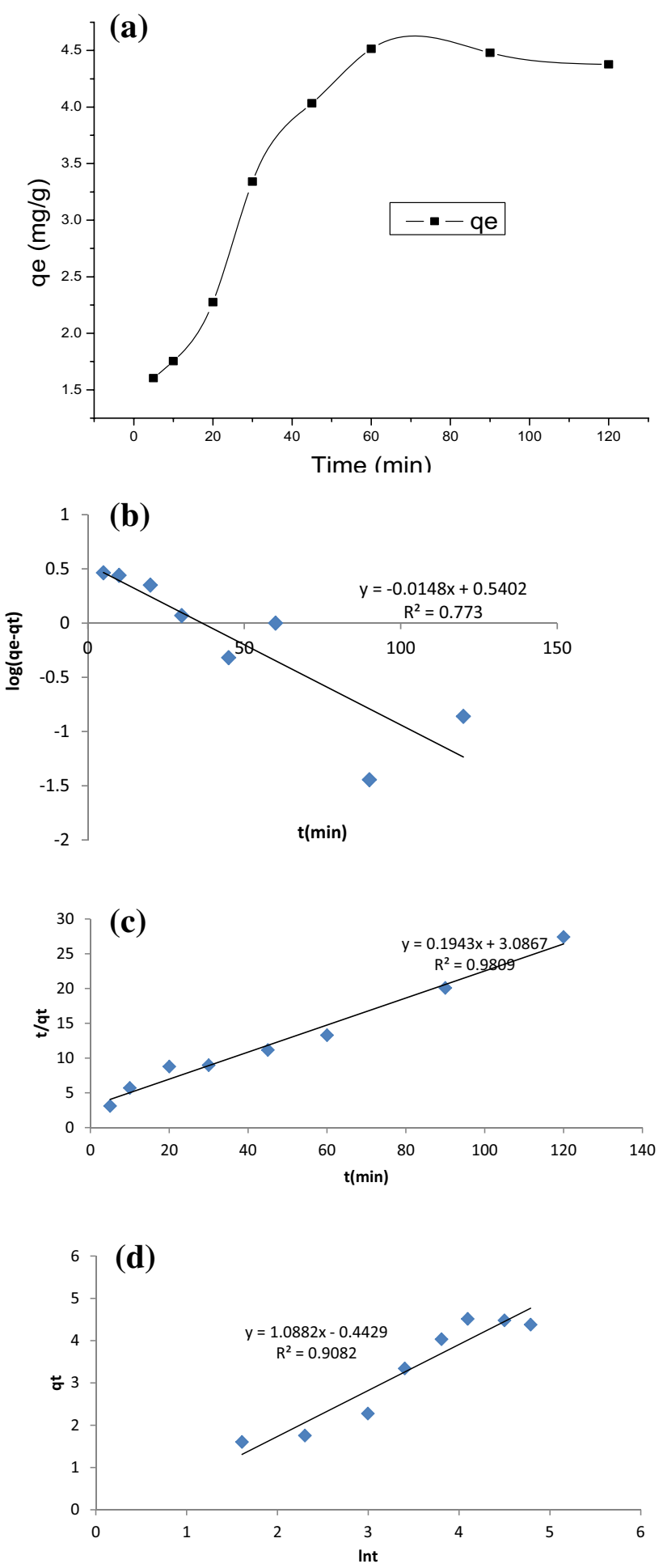

Fig. 4 a Effect of time on the sorption of BPA onto $\mathrm{nFe}_{3} \mathrm{O}_{4}$. b Pseudo-first-order kinetic plot. c Pseudo-second-order kinetic plot. d Elovich kinetic model plot 
Table 3 Kinetics parameters

\begin{tabular}{lll}
\hline Kinetics model & Parameters & Values \\
\hline Pseudo-first order & $q_{\mathrm{e}}$ & 3.467 \\
& $k_{1}$ & 0.032 \\
& $R^{2}$ & 0.773 \\
Pseudo-second order & $q_{\mathrm{e}}$ & 5.515 \\
& $k_{2}$ & 0.012 \\
Elovich & $R^{2}$ & 0.980 \\
& $\alpha$ & 0.919 \\
& $\beta$ & 0.725 \\
& $R^{2}$ & 0.908 \\
\hline
\end{tabular}
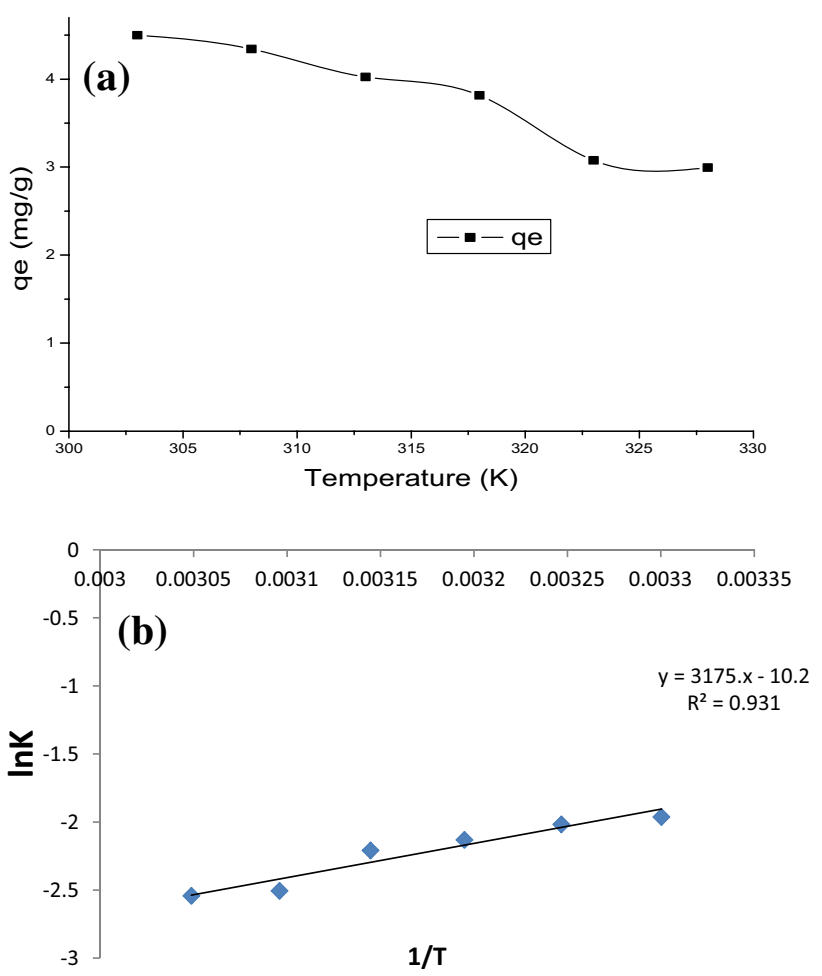

Fig. 5 a Effect of temperature on the sorption of BPA onto $\mathrm{nFe}_{3} \mathrm{O}_{4}$. b Thermodynamic plot

Table 4 Thermodynamic parameters

\begin{tabular}{lllc}
\hline$\Delta H\left(\mathrm{Jmol}^{-1}\right)$ & $\Delta S\left(\mathrm{Jmol}^{-1}\right)$ & $\begin{array}{l}\text { Temperature } \\
(\mathrm{K})\end{array}$ & $\Delta G\left(\mathrm{Jmol}^{-1}\right)$ \\
\hline-26396.95 & -84.8028 & 303 & -701.702 \\
& 308 & -277.688 \\
& 313 & 146.3264 \\
& 318 & 570.3404 \\
& 323 & 994.3544 \\
& 328 & 1418.368 \\
\hline
\end{tabular}

Gibb's free energy value which was negative showed that the adsorption was spontaneous. The synthesized magnetite therefore offers great potential for the remediation of bisphenol A-contaminated media.

Open Access This article is distributed under the terms of the Creative Commons Attribution 4.0 International License (http://creativeco mmons.org/licenses/by/4.0/), which permits unrestricted use, distribution, and reproduction in any medium, provided you give appropriate credit to the original author(s) and the source, provide a link to the Creative Commons license, and indicate if changes were made.

\section{References}

Adekola FA, Hodonou DSS, Adegoke HI (2014) Thermodynamic and kinetic studies of biosorption of iron and manganese from aqueous medium using rice husk ash. Appl Water Sci 1:1-12

Ahmaruzzaman M (2008) Adsorption of phenolic compounds on lowcost adsorbents: a review. Adv Colloid Interface Sci 143:48-67

Balci B, Erkurt FE (2017) Adsorption of Bisphenol-A by Eucalyptus bark/magnetite composite: modeling the effect of some independent parameters by multiple linear regression. Adsorpt Sci Technol 35(3-4):339-356

Brugnera MF, Rajeshwar K, Cardoso JC, Zanoni MVB (2010) Bisphenol A removal from wastewater using self-organized $\mathrm{TiO}_{2}$ nanotubular array electrodes. Chemosphere 78:569-575

Chen PJ, Linden KG, Hinton DE, Kashiwada S, Rosenfeldt EJ, Kullman SW (2006) Biological assessment of bisphenol A degradation in water following direct photolysis and UV advanced oxidation. Chemosphere 65:1094-1102

Coleman HM, Chiang K, Amal R (2005) Effects of Ag and Pt on photocatalytic degradation of endocrine disrupting chemicals in water. Chem Eng J 113:65-72

Dehghani MH, Ghadermazic M, Bhatnagard A, Sadigharae P, JahedKhanikie G, Heibatia B, McKayf G (2016) Adsorptive removal of endocrine disrupting bisphenol A from aqueous solution using chitosan. J Environ Chem Eng 4:2647-2655

Du J, Bao J, Liu Y, Ling H, Zheng H, Kim SH, Dionysiou DD (2016) Efficient activation of peroxymonosulfate by magnetic Mn-MGO for degradation of bisphenol A. J Hazard Mater 320:150-159

Fan J, Yang W, Li A (2011) Adsorption of phenol, bisphenol A and nonylphenol ethoxylates onto hypercrosslinked and aminated adsorbents. React Funct Polym 71:994-1000

Hamid K, Abolghasem A, Fereshteh R (2012) Synthesis of magnetite nano-particles by reverse coprecipitation. Int J Mod Phys Conf Ser 5:160-167

Han W, Luo L, Zhang S (2012) Adsorption of bisphenol A on lignin: effects of solution chemistry. Int J Environ Sci Technol 9(3):543-548

Heo J, Flora JR, Her N, Park YG, Cho J, Son A, Yoon Y (2012) Removal of bisphenol A and 17b-estradiol in single walled carbon nanotubes-ultrafiltration (SWNTs-UF) membrane systems. Sep Purif Technol 90:39-52

Hugo ER, Brandebourg TD, Woo JG, Loftus J, Alexander JW, BenJonathan N (2008) Bisphenol A at environmentally relevant doses inhibits adiponectin release from human adipose tissue explants and adipocytes. Environ Health Persp 116:1642

Inoue M, Masuda Y, Okada F, Sakurai A, Takahashi I, Sakakibara M (2008) Degradation of bisphenol A using sonochemical reactions. Water Res 42:1379-1386 
Irmak S, Erbatur O, Akgerman A (2005) Degradation of 17 $\beta$-estradiol and bisphenol $\mathrm{A}$ in aqueous medium by using ozone and ozone/ UV techniques. J Hazard Mater B126:54-62

Ivanov AE, Halthur T, Ljunggren L (2016) Flow permeable composites of lignin and poly(vinyl alcohol): towards removal of bisphenol A and erythromycin from water. J Environ Chem Eng 4:1432-1441

Jafari R, Abasabad A, Salehzadeh A (2009) Endocrine disrupting contaminants in water resources and sewage in Hamadan City of Iran, Iran. J Environ Health Sci Eng 6:89-96

Jiang T, Liu W, Mao Y, Zhang L, Cheng J, Gong M, Zhao H, Dai L, Zhang S, Zhao Q (2015) Adsorption behavior of copper ions from aqueous solution onto graphene oxide-CdS composite. Chem Eng J 259:603-610. https://doi.org/10.1016/j.cej.2014.08.022

Jin Z, Wang X, Sun Y, Ai Y, Wang X (2015) Adsorption of 4-n-Nonylphenol and Bisphenol-A on magnetic reduced graphene oxides: a combined experimental and theoretical studies. Environ Sci Technol 49:9168-9175

Joseph L, Heo J, Park YG, Flora JRV, Yoon Y (2011) Adsorption of bisphenol A and 17 $\alpha$-ethinyl estradiol on single walled carbon nanotubes from seawater and brackish water. Desalination 281:68-74

Kuramitz H, Nakata Y, Kawasaki M, Tanaka S (2001) Electrochemical oxidation of bisphenol A. Application to the removal of bisphenol A using a carbon fiber electrode. Chemosphere 45:37-43

Li GL, Jiang YR, Huang KL, Ding P, Yao II (2008) Kinetics of adsorption of saccharomyces cerevisiae mandelated dehydrogenase on magnetic $\mathrm{Fe}_{3} \mathrm{O}_{4}$-chitosan nanoparticles. J Colloid Interface Sci 320(A):11-18

Liu G, Ma J, Li X, Qin Q (2009) Adsorption of bisphenol A from aqueous solution onto activated carbons with different modification treatments. J Hazard Mater 164:1275-1280

Nakanishi M, Tamai N, Kawasaki T, Nakamura ST (2002) Adsorption characteristics of bisphenol A onto carbonaceous materials produced from wood chips as organic waste. J Colloid Interface Sci 252:393-396

Pan B, Lin D, Mashayekhi H, Xing B (2008) Adsorption and hysteresis of bisphenol A and $17 \alpha$-ethinyl estradiol on carbon nanomaterials. Environ Sci Technol 42:5480-5485

Park HS, Koduru JR, Choo KH, Lee B (2015) Activated carbons impregnated with iron oxide nanoparticles for enhanced removal of bisphenol A and natural organic matter. J Hazard Mater 286:315-324

Radu E, Ion AC, Sirbu F, Ion I (2015) Adsorption of endocrine disruptors on exfoliated Graphene nanoplatelets. Environ Eng Manag J 14(3):551-558

Rastegari M, Saeedi M, Mollahosseini A, Ayatynia M (2016) Phenanthrene sorption onto kaolinite; heavy metals and organic matter effects. Int J Environ Res 10(3):441-448

Santhi VA, Sakai N, Ahmad ED, Mustafa AM (2012) Occurrence of bisphenol $\mathrm{A}$ in surface water, drinking water and plasma from
Malaysia with exposure assessment from consumption of drinking water. Sci Total Environ 5:427-428

Shirsath DS, Shrivastava VS (2015) Photocatalytic removal of $O$-Nitro phenol from wastewater by novel an eco-friendly magnetic nanoadsorbent. Int J Environ Res 9(1):363-372

Soares A, Guieysse B, Jefferson B, Cartmell E, Lester J (2008) Nonylphenol in the environment: a critical review on occurrence, fate, toxicity and treatment in wastewaters. Environ Int 34:1033-1049

Staples CA, Dome PB, Klecka GM, Oblock ST, Harris LR (1998) A review of the environmental fate, effects, and exposures of bisphenol A. Chemosphere 36:2149-2173

Tang T, Fan H, Ai S, Han R, Qiu Y (2011) Hemoglobin (Hb) immobilized on amino-modified magnetic nanoparticles for the catalytic removal of bisphenol A. Chemosphere 83:255-264

Vandenberg LN, Hauser R, Marcus M, Olea N, Welshons WV (2007) Human exposure to bisphenol A (BPA). Reprod Toxicol 24(2):139-177

Wang P, Wang X, Yu S, Zou Y, Wang J, Chen Z, Alharbi NS, Alsaedi A, Hayat T, Chen Y, Wang X (2016) Silica coated $\mathrm{Fe}_{3} \mathrm{O}_{4}$ magnetic nanospheres for high removal of organic pollutants from wastewater. Chem Eng J 306:280-288

Wu SH, Dong B, Huang Y (2010) Adsorption of bisphenol A by polysulphone membrane. Desalination 253:22-29

Xiao G, Fu L, Li A (2012) Enhanced adsorption of bisphenol A from water by acetylaniline modified hyper-cross-linked polymeric adsorbent: effect of the cross-linked bridge. Chem Eng J 191:171-176

Yeo MK, Kang M (2006) Photodecomposition of bisphenol A on nanometer-sized $\mathrm{TiO}_{2}$ thin film and the associated biological toxicity to zebrafish (Danio rerio) during and after photocatalysis. Water Res 40:1906-1914

Zeng C, Zhang G, Huang J, Yu Q, Wang J, Xi B, Liu H (2006) Adsorption behavior of bisphenol a on sediments in Xiangjiang River, Central-south China. Chemosphere 65:1490-1499

Zhang Y, Cheng Y, Chen N, Zhou Y, Li B, Gu W, Shi X, Xian Y (2014) Recyclable removal of bisphenol A from aqueous solution by reduced graphene oxide-magnetic nanoparticles: adsorption and desorption. J Colloid Interface Sci 421:85-92

Zou Y, Wang X, Khan A, Wang P, Liu Y, Alsaedi A, Hayat T, Wang X (2016) Environmental remediation and application of nanoscale zero- valent iron and its composites for the removal of heavy metal ions: a review. Environ Sci Technol 50:7290-7304

Publisher's Note Springer Nature remains neutral with regard to jurisdictional claims in published maps and institutional affiliations. 